\title{
RESPONSE ANALYSIS OF FIR HIGH PASS FILTER DESIGN USING WINDOW METHODS
}

\author{
N. M. Shehu, A.S. Gidado, M.I. Faruk \\ Department of Physics, Bayero University, \\ Kano, Nigeria
}

\begin{abstract}
Filters are widely employed in signal processing and communication systems in applications such as channel equalization, noise reduction, radar, audio processing, video processing, biomedical signal processing, and analysis of economic and financial data. Window methods are prominently used in the design of digital FIR filter. The paper studies the comparative analysis of a proposed high pass FIR filter design using Kaiser, Rectangular and Tukey window methods with the aid of FDATOOL in MATLAB. From the comparative analysis Rectangular is found to be the best for the proposed filter design based on the magnitude responses of the three windows.
\end{abstract}

Keywords: MATLAB, DSP, Window Method, Magnitude response.

\section{INTRODUCTION}

In many applications of signal processing we want to change the relative amplitudes and frequency contents of a signal. This process is generally referred to as filtering. Since the Fourier transform of the output is product of input Fourier transform and frequency response of the system, we have to use appropriate frequency response. Digital signal processing techniques are used in a variety of areas which include set top box, spread spectrum, cable modems, video compression, robotic vision, speech processing, image processing, RADAR, SONAR, etc. These techniques are applied in spectral analysis, channel vocoders, homomorphic processing systems, speech synthesizers, linear prediction systems, analyzing the signal in radar tracking, etc.

The attraction of DSP comes from key advantages such as guaranteed accuracy, perfect reproducibility, greater flexibility and superior performance (Emmanuel et al., 2004). Digital filter is important class of Linear time invariant DSP systems designed to modify the frequency characteristics of the input signal $\mathrm{x}(\mathrm{n})$ to meet certain specific design requirements. Digital filters are widely used because of certain advantages over Analog filters. Digital filters have the potential to attain much better signal to noise ratios than Analog filters. Digital Filters have emerged as a strong option for removing noise, shaping spectrum and minimizing inter-symbol interference (ISI) in communication architectures (Marthy, 2008).

\section{A. FIR Filter}

Finite impulse response (FIR) filter is a filter whose impulse response (or response to any finite length input) is of finite duration, because it settles to zero in finite time. A finite impulse response (FIR) filter is a filter structure that can be used to implement almost any sort of frequency response digitally. An FIR filter is usually implemented by using a series of delays, multipliers and adders to create the filter's output. FIR filters also known as feed forward or non-recursive, or transversal filters. The unit impulse response is finite; so FIR filters are stable system.

FIR filters are employed in filtering problems where linear phase characteristics within the passband of the filter is required. If this is not required, either an IIR or an FIR filter may be employed. An IIR filter has lesser number of side lobes in the stopband that than FIR filter with the same number of parameters. For this reason, if some phase distortion is tolerable, an IIR filter is preferable. Also, the implementation of an IIR involves fewer parameters, less memory requirements and lower computational complexity.

\section{B. FIR Filter Design Methods}

FIR filter design consists of Approximation problem and Realization problem. The approximation stage gives transfer function. Realization part deals with choosing the structure to implement the transfer function which may be in the form of circuit diagram or in the form of a program. There are three common methods for filter design one is the window method 
(Yan, 2010), it truncates the Fourier series. Second is the frequency sampling technique (Ammar et al., 2013) by using this method set of samples can be obtained in frequency domain. In Second method Frequency response of the filter is same as obtained at the sampling instant (Spanias, 2004). Third method is the optimal filter design method (Ran et al., 2014). Window method is used throughout this paper.

\section{Window Method}

Window technique involves a function called window function or apodization function which states that if some interval is chosen, it returns with finite nonzero value inside that interval and zero value outside that interval. So, if the window with chosen interval is applied on a IIR system, it will obviously return with a finite non-zero value inside that interval producing a FIR system and all other value that are outside the interval will be zero. So, we can view the finite response inside some predefined interval (Sarita et al., 2012) (Datar et al., 2009) (Sonika et al., 2012) (Shanoi, 2006) (Li, 2008) (Andreas, 2006).

There are many window techniques available for designing the FIR filter and they are (Bob, 2000) (Ramesh et al., 2012) (Babu, 2008) (Andreas, 2006):
a. Hanning Window
b. Hamming Window
c. Blackman Window
d. Rectangular Window
e. Bartlett Window
f. Kaiser Window.

In this research paper, we compare and analyze Rectangular, Kaiser and Tukey window methods.

\section{Rectangular Window}

Rectangular window is the simplest window function for FIR filter design. The function can be stated as follows:

$$
w(n)= \begin{cases}1, & n=0,1,2 \ldots ., M-1, \\ 0, & \text { otherwise }\end{cases}
$$

The unit sample response of the FIR filter becomes:

$$
h(n)=h_{d}(n) w(n)
$$

Where $h_{d}(n)$ is the desired impulse response filter.

$$
h(n)= \begin{cases}h_{d}(n), & n=0,1,2 \ldots ., M-1, \\ 0, & \text { otherwise }\end{cases}
$$

The Fourier Transform of $w(n)$ gives the frequency domain representation of the window.

\section{E. Kaiser Window}

The Kaiser Window function can be written as (Patel et al., 2013):

$$
W(n)=\left\{\begin{array}{cl}
\operatorname{Io}(\beta \sqrt{1-(2(n+1)(N+1)}, & \text { from }=0 \text { to } n-1 \\
0, & \text { elsewhere }
\end{array}\right.
$$

\section{F. Tukey Window}

The Tukey window is also called the tapered cosine Window. The Tukey Window is defined as (Goyal et al., 2015):

$$
\mathrm{W}_{\tau}(\mathrm{n})=\left\{\begin{array}{c}
\frac{1}{2}\left[1+\cos \left(\pi\left(\frac{2 n}{\alpha(M-1)}-1\right)\right)\right], \\
0 \leq n \leq \frac{\alpha(M-1)}{2} \\
1 \quad, \frac{\alpha(M-1)}{2} \leq n \leq(M-1)\left(1-\frac{\alpha}{2}\right) \\
\frac{1}{2}\left[1+\cos \left(\pi\left(\frac{2 n}{\alpha(M-1)}-\frac{2}{\alpha}+1\right)\right)\right], \\
(M-1)\left(1-\frac{\alpha}{2}\right) \leq n \leq(M-1)
\end{array}\right.
$$

\section{METHODOLOGY}

A proposed high pass FIR filter using Tukey, Kaiser and Rectangular window methods has been designed with the aid of FDATOOL in MATLAB. The table 1 below shows the parameter specifications used for the proposed design.

Table 1: Parameter Specifications

\begin{tabular}{|c|c|l|c|c|c|}
\hline $\begin{array}{c}\text { Windo } \\
\text { w }\end{array}$ & $\begin{array}{l}\text { Sampl } \\
\text { ing } \\
\text { freque } \\
\text { ncy, } \\
\text { fs(MH } \\
\text { z) }\end{array}$ & $\begin{array}{l}\text { Cut- } \\
\text { off } \\
\text { freque } \\
\text { ncy, } \\
\text { fc(MH } \\
\text { z) }\end{array}$ & $\begin{array}{l}\text { Order } \\
(\mathbf{N})\end{array}$ & $\begin{array}{l}\text { Alph } \\
\mathbf{a ( \alpha )}\end{array}$ & $\begin{array}{l}\text { Beta } \\
(\boldsymbol{\beta})\end{array}$ \\
\hline $\begin{array}{l}\text { Rectan } \\
\text { gular }\end{array}$ & 48 & 10.8 & 50 & - & - \\
\hline Kaiser & 48 & 10.8 & 50 & - & 0.5 \\
\hline
\end{tabular}




\begin{tabular}{|l|l|l|l|l|l|}
\hline Tukey & 48 & 10.8 & 50 & 0.5 & \\
\hline
\end{tabular}

\section{SIMULATION RESULTS AND DISCUSSION}

Using the specified parameters from table 1 the proposed high pass FIR filter is designed with the aid of FDATOOL in MATLAB. The simulation results of the three windows are shown in figures 1 to 12 .

\section{A. Rectangular Window Simulations}

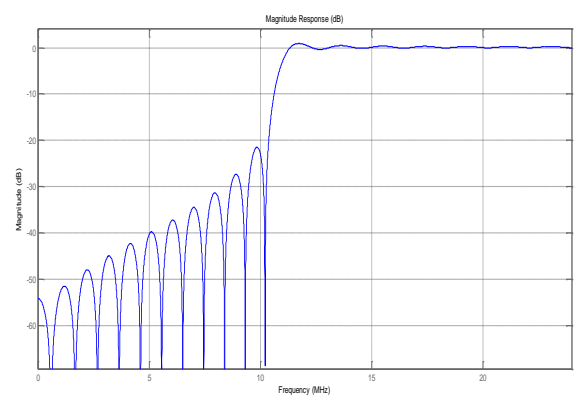

Fig. 1: Magnitude response for Rectangular window.

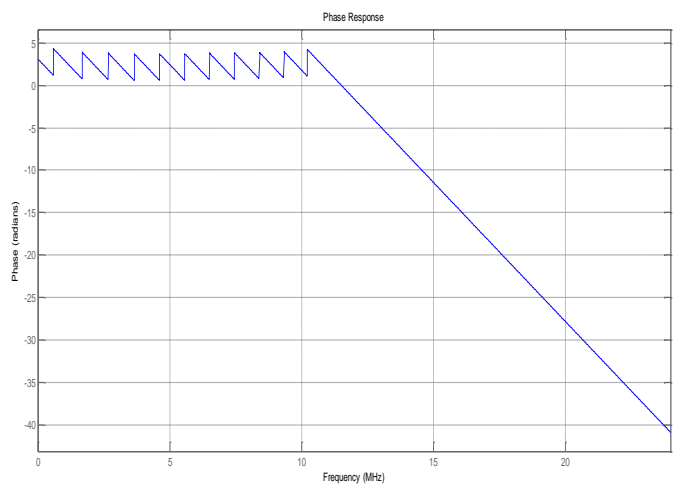

Fig. 2: Phase response for Rectangular window.

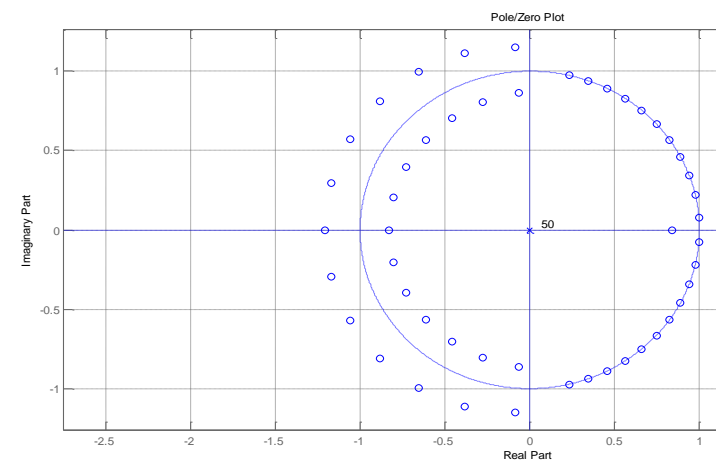

Fig. 3: Pole/Zero for Rectangular window.

Figures 1 to 3 above show the simulation results of Rectangular window. The magnitude response, phase response and the pole/zero are all plotted. The magnitude response cuts at exactly $10.22 \mathrm{MHz}$ with gap of $0.58 \mathrm{MHz}$ between the specified cut off frequency $(10.8 \mathrm{MHz})$. The phase also changes at 10.22 MHz.

\section{B. Kaiser Window Simulations}

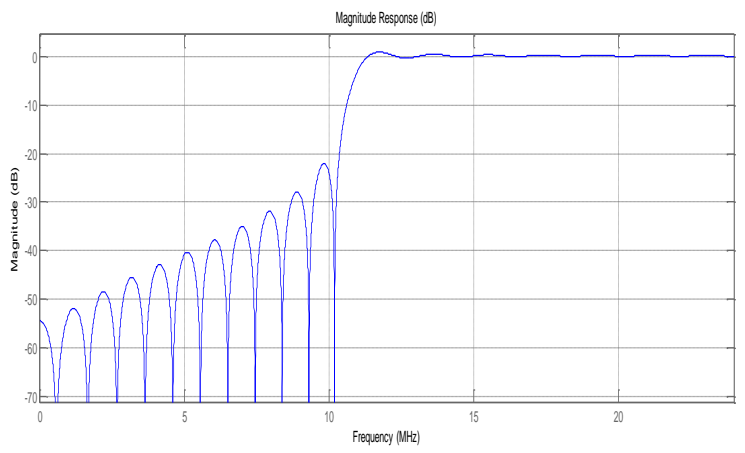

Fig. 4: Magnitude response for Kaiser Window.

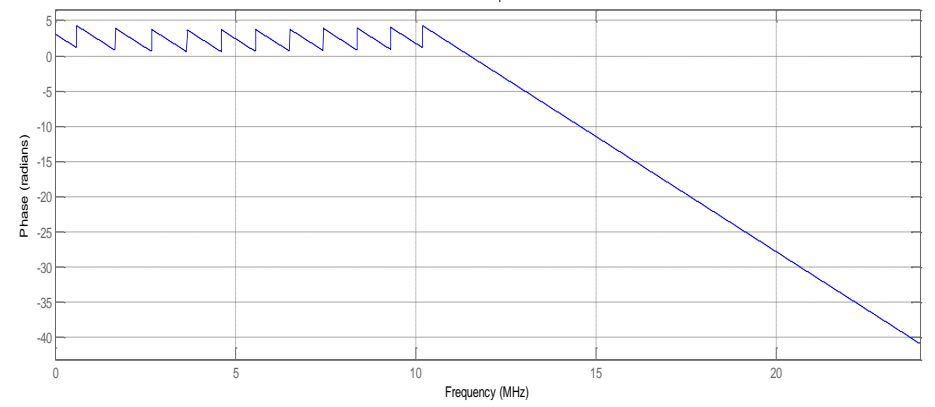

Fig. 5: Phase response for Kaiser Window.

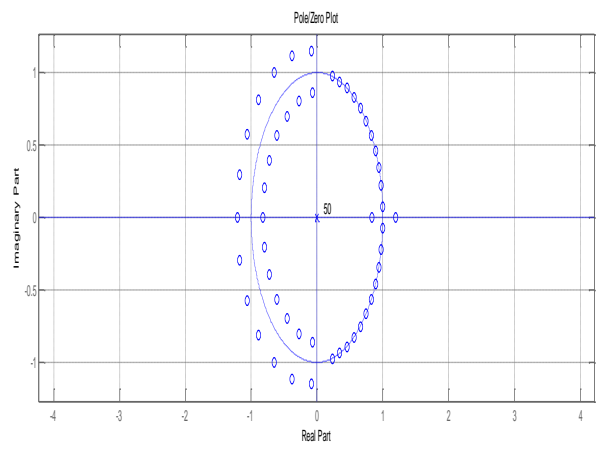

Window.

Fig. 6: Pole/Zero for Kaiser

Figures 4 to 6 above show the simulation results of Kaiser Window. The magnitude response, phase response and the pole/zero are all plotted. The magnitude response cuts at exactly $10.16 \mathrm{MHz}$ with gap of $0.64 \mathrm{MHz}$ between the specified cut off frequency $(10.8 \mathrm{MHz})$. The phase changes at 10.20 MHz. 


\section{Tukey Window Simulations}

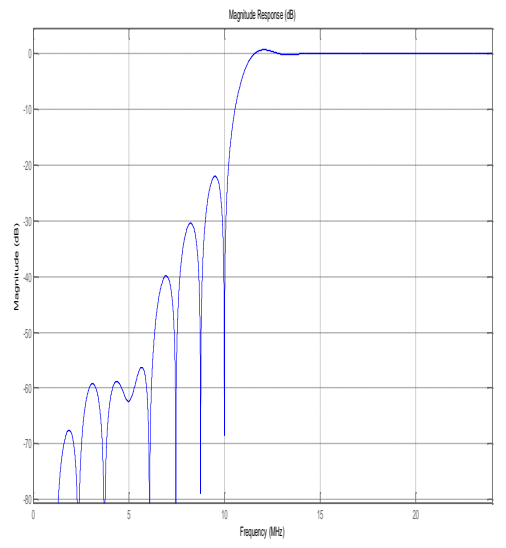

Fig. 7: Magnitude response for Tukey Window.

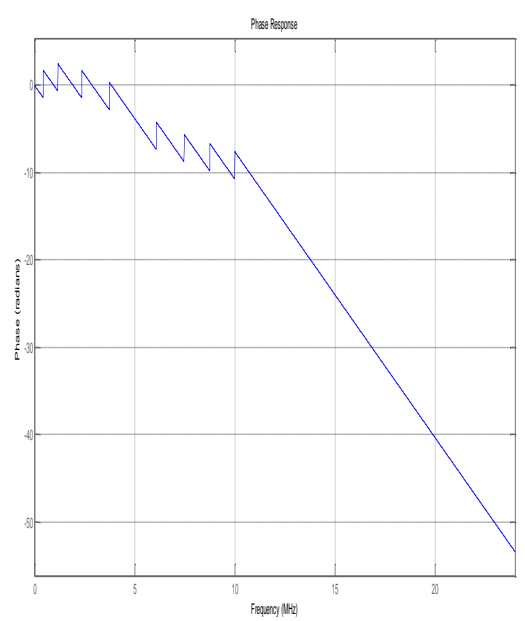

Fig. 8: Phase respose for Tukey Window.

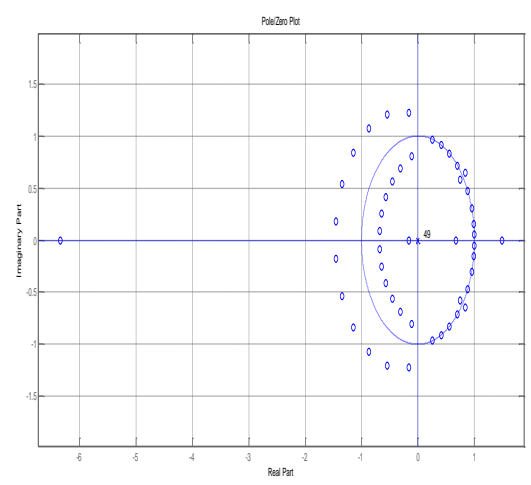

Fig. 9: Pole/Zero for Tukey Window.

Figures 7 to 9 above show the simulation results of Tukey window. The magnitude response, phase response and the pole/zero are all plotted. The magnitude response cuts at exactly $10.00 \mathrm{MHz}$ with gap of $0.8 \mathrm{MHz}$ between the specified cut off frequency $(10.8 \mathrm{MHz})$. The phase changes at 10.06 MHz.

\section{COMPARATIVE ANALYSIS}

The magnitude responses, phase responses and pole/zero plots are combined in a single diagram for comparison as shown in the figures 10-12 below.

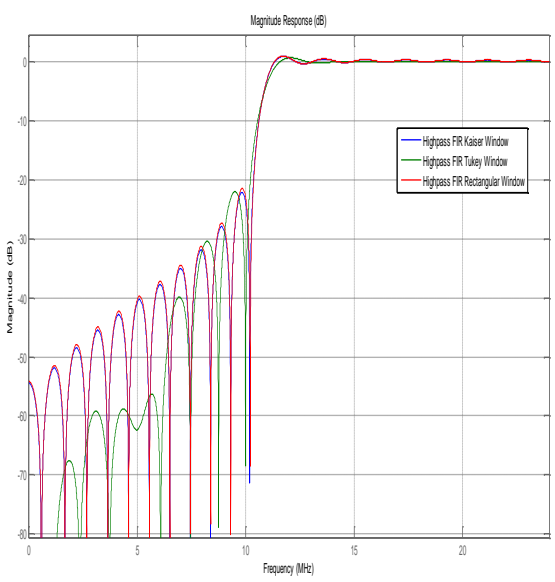

Fig. 10: Comparison among magnitude responses.

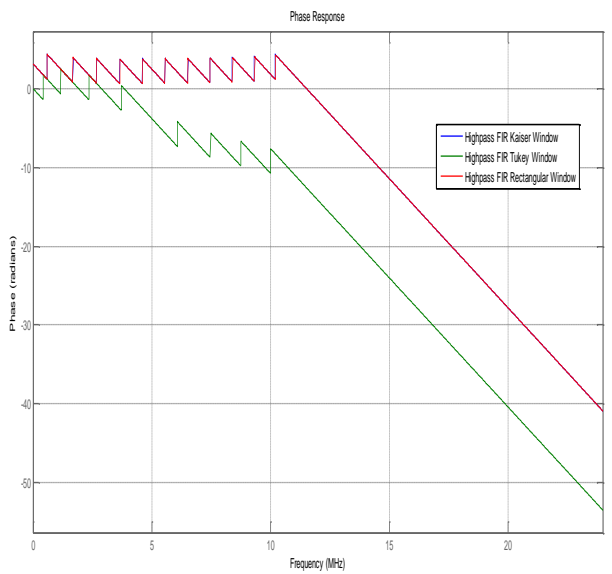

Fig. 11: Comparison among phase responses.

In fig. 10 above, the magnitude responses of the Rectangular, Kaiser and Tukey windows are plotted together on a single figure for comparison. From the figure, it can be observed that Rectangular window cuts at $10.22 \mathrm{MHz}$, Kaiser window cuts at $10.16 \mathrm{MHz}$ and Tukey cuts at $10.00 \mathrm{MHz}$. Based on the magnitude response comparison, Rectangular which cuts at 10.22 $\mathrm{MHz}$ is 0.58 below the exact specified cut off frequency $(10.8 \mathrm{MHz})$, Kaiser which cuts at 10.16 
$\mathrm{MHz}$ is 0.64 below the specified cut off frequency and Tukey which cuts at $10.00 \mathrm{MHz}$ is 0.8 below the specified cut off frequency in the design.

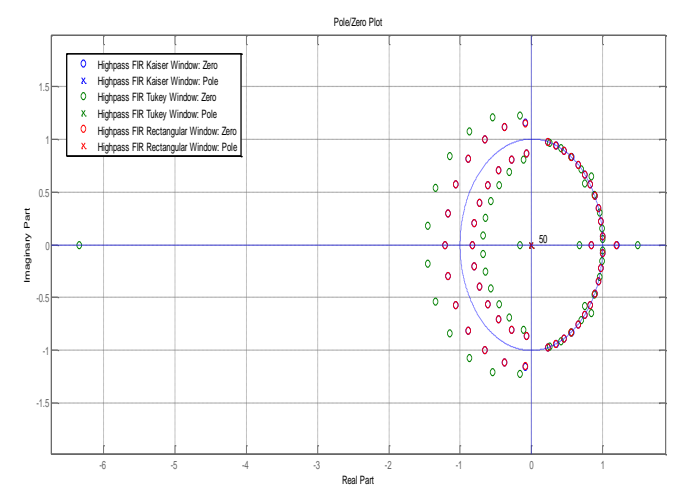

Fig. 12: Comparison among pole/zero plots.

Table 2: Parameter comparison among the three windows.

\begin{tabular}{|l|l|l|l|l|}
\hline $\begin{array}{l}\text { S/ } \\
\text { N }\end{array}$ & Parameter & $\begin{array}{l}\text { Rectangu } \\
\text { lar }\end{array}$ & Kaiser & Tukey \\
\hline 1 & $\begin{array}{l}\text { Magnitude } \\
\text { response(M } \\
\text { Hz) }\end{array}$ & $\begin{array}{l}\text { Cuts at } \\
10.22\end{array}$ & $\begin{array}{l}\text { Cuts at } \\
10.16\end{array}$ & $\begin{array}{l}\text { Cuts at } \\
10.00\end{array}$ \\
\hline 2 & $\begin{array}{l}\text { Phase } \\
\text { response(M } \\
\text { Hz) }\end{array}$ & $\begin{array}{l}\text { Changes } \\
\text { at } 10.22\end{array}$ & $\begin{array}{l}\text { Chang } \\
\text { es at } \\
10.20\end{array}$ & $\begin{array}{l}\text { Chang } \\
\text { es at } \\
10.06\end{array}$ \\
\hline 3 & $\begin{array}{l}\text { Leakage } \\
\text { factor }\end{array}$ & $9.25 \%$ & $8.4 \%$ & $3.61 \%$ \\
\hline 4 & $\begin{array}{l}\text { Relative } \\
\text { Sideband } \\
\text { Attenuation }\end{array}$ & $-13.3 \mathrm{~dB}$ & $\begin{array}{l}- \\
13.6 \mathrm{~d} \\
\mathrm{~B}\end{array}$ & $\begin{array}{l}- \\
15.1 \mathrm{D} \\
\mathrm{b}\end{array}$ \\
\hline 5 & Stable & Yes & Yes & Yes \\
\hline
\end{tabular}

There are various parameters upon which the comparative analysis can be made among the Rectangular, Kaiser and Tukey windows. Viewing closely figure 10 which compares the magnitude responses of the windows, it can be observed that Rectangular window cuts at $10.22168 \mathrm{MHz}$ which is clearly closest to $10.8 \mathrm{MHz}$ cut off frequency used for the proposed design. On the basis of magnitude responses, Rectangular windows appears to be the best for the proposed design.

\section{CONCLUSION}

This paper studies the comparative analysis of a proposed high pass FIR filter using Rectangular, Kaiser and Tukey window methods. The study shows that Rectangular window is the best for the proposed filter design based on the magnitude responses of the three windows. This is because the magnitude response of the rectangular window is found to be the closest to the specified cut off frequency in the design.

\section{ACKNOWLEDGEMENT}

We would like to thank Prof. Garba Babaji, Department of Physics, Bayero University, Kano, Nigeria for his valuable suggestions. We would also like to thank our department for providing us with all what it takes to make our research work successful. We also express our gratitude to our parents, friends and colleagues.

\section{REFERENCES}

1. Bob, Meddins (2000). Introduction to Digital Signal Processing. Essential Electronics Series, Newnes, Butterworth-Heinemann, Oxford, ISBN: 0750650486.

2. Emmanuel, CI; Barrie, WJ (2004). Digital Signal Processing, Second Edition, Pearson Publication, pp. 02-40.

3. Marthy, GR (2008). Finite Impulse Response FIR filter Model of Synapses: Associated Neural Network, Proceeding of the Fourth Annual IEEE International Confidences on Natural Computation 3304 - 3309.

4. Sarita, Chouhan; Yogesh, Kumar (2012). Low power designing of FIR filters. International Journal of Advanced Technology \& Engineering Research 2(2), 59- 67.

5. Datar; A; Jain, AS; P, C (2009). Performance of Blackman window family in M-channel cosine modulated filter bank for ECG signal, Multimedia, Signal Processing and Communication Technologies. IMPACT '09. International, IEEE Conference, Aligarh, ISBN: 978-1-4244-3602-6, pp 98 - 101.

6. Sonika, Gupta; Aman, Panghal (2012). Performance Analysis of FIR Filter Design by Using Rectangular, Hanning and Hamming Windows Methods. International Journal of Advanced Research in Computer Science and Software Engineering 2(6), 273277.

7. Shanoi, BA (2006). Introduction to Digital Signal Processing and Filter design. Willey Interscience.

8. Li, Tan (2008). Digital Signal ProcessingFundamentals and Applications. Academic Press, Elsevier, ISBN: 978-0-12-374090-8. 
9. Andreas, Antoniou (2006). Digital Signal Processing: Signals, Systems and Filters. Tata McGraw-Hill Education, ISBN-10: 0070636338.

10. Patel, R; M, Kumar; AK, Jaiswal; R, Saxena (2013). Design technique of band pass FIR filter using various window function. IOSR journal of electronics and communication engineering 6(6), 52-57.

11. Ramesh, .R; Nathiya, .R (2012). Realization of fir filter using modified distributed arithmetic architecture. Signal \& Image Processing: An International Journal (SIPIJ) 3(1), 83-94.

12. Babu, PR (2008). Digital Signal Processing. Fourth edition, Scitech Publication (India) Pvt. Ltd, Chennai.

13. Yan, G; Z, Lin-Lin (2010). Simulation Study of FIR Filter Based on MATLAB. IEEE.

14. Spanias, A; C, Panayiotou; V, Atti (2004). Graphical design of frequency sampling Filters use in a signals and systems laboratory IEEE.

15. Ammar, AA; MK, Julboub; AA, Elmghairbi (2013). Digital filter design (FIR) using frequency sampling method. University bulletin 3(15) pp. 39-48.

16. Ran, ZX; WY, Duo (2014). Digital filter design and analysis of BSF based on the best approximation method of Equiripple. IEEE, pp. 113- 116.

17. Goyal, Divya; Goel, Ritesh (2015). Review of Low-Pass FIR Filter Design Using Window Method. International Journal of Advanced Research in Electronics and Communication Engineering (IJARECE) 4(7), 1975-1978. 